\title{
Case Report \\ Recovery of Renal Function after One-Year of Dialysis Treatment: Case Report and Registry Data
}

\author{
Ingela Fehrman-Ekholm, ${ }^{1}$ Ann-Charlotte Bergenhag, ${ }^{1}$ Olof Heimburger, ${ }^{2}$ \\ and Staffan Schön ${ }^{3}$ \\ ${ }^{1}$ Dialysis Unit, Sophiahemmet, Karolinska University Hospital, P.O. Box 5605, 11486 Stockholm, Sweden \\ ${ }^{2}$ Department of Renal Medicine, Karolinska University Hospital, P.O. Box 5605, 14186 Stockholm, Sweden \\ ${ }^{3}$ Swedish Renal Registry (SRR), Medicinexp, plan 5, Länssjukhuset Ryhov, 55185 Jönköping, Sweden
}

Correspondence should be addressed to Ingela Fehrman-Ekholm, ingela.fehrman@sophiahemmet.se

Received 23 December 2009; Revised 17 March 2010; Accepted 12 April 2010

Academic Editor: Rajnish Mehrotra

Copyright (c) 2010 Ingela Fehrman-Ekholm et al. This is an open access article distributed under the Creative Commons Attribution License, which permits unrestricted use, distribution, and reproduction in any medium, provided the original work is properly cited.

\begin{abstract}
Objective. Uncertainty has arisen as to whether renal function can be recovered from after long-term regular dialysis treatment. We therefore conducted an analysis and scrutinized one patient report. Material and Methods. Swedish registry of patients with kidney disease and one patient case. Results. 39 patients $(0.2 \%)$ from the Swedish registry comprising 17590 patients who commenced RRT (renal replacement therapy) between 1991 and 2008 had recovered from renal function after more than 365 days of regular dialysis treatment. The most common diagnosis was renovascular disease with hypertension but a large group had uremia of unknown cause. HUS, cortical/tubular necrosis, and autoimmune diseases were also found. The mean treatment time before withdrawal was 2 years. Conclusions. A small number of patients recover after a long period of regular dialysis treatment. One could discuss whether it is difficult to identify patients who have recovered while undergoing regular dialysis treatment. Regular monitoring of renal function may be important.
\end{abstract}

\section{Introduction}

Recovery of renal function in end-stage renal disease in patients receiving renal replacement therapy has been described as occurring in $0.3 \%-8 \%$ [1-3]. A recent study from Australia revealed that recovery occurred in $1 \%$ of the dialysis population and there was no difference between $\mathrm{PD}$ or $\mathrm{HD}$ [4]. In the literature the cases of recovery have included various diagnoses: surgery after total renal artery arteriosclerosis, cholesterol crystal embolism, FSGS secondary to HIV, secondary oxalosis, and accelerated hypertension.

Having experienced a patient who was taken off from dialysis treatment after 15 months and who 18 months after this process is still in no need of regular dialysis motivated us to present the case and scrutinize the Swedish registry to find similar cases with dialysis treatment of more than one year followed by withdrawal. We considered it important to establish the diagnoses behind the diseases that could abate after such a long treatment period.

\section{Results}

We present our case report.

2.1. Case Report. A healthy 49-year-old man developed acute problems with headache and vomiting. He was admitted to hospital in November 2006. It was found that his blood pressure was high measuring $228 / 138 \mathrm{~mm} \mathrm{Hg}$ in the left arm and 205/145 in the right arm, kidney function poor with creatinine $997 \mu \mathrm{mol} / \mathrm{L}$, anemia with $\mathrm{Hb} 90 \mathrm{~g} / \mathrm{L}$, and thrombocytopenia with platelets $40 \times 10^{9} / \mathrm{L}$. Further investigation revealed that lactate dehydrogenase (LD) was elevated to $38.2 \mu \mathrm{cat} / \mathrm{L}(N V<3.5 \mu \mathrm{cat} / \mathrm{L})$ and aspartaminotranspheras (ASAT) to $1.67 \mu \mathrm{cat} / \mathrm{L}(N V<0.76 \mu \mathrm{cat} / \mathrm{L})$. The 
TABLE 1: Characteristics of the patient in whom dialysis was withdrawn after 16 months of RRT.

\begin{tabular}{|c|c|c|c|c|c|c|c|c|c|c|}
\hline Time & Nov. 2006 & May 2007 & Jan. 2008 & Mar. 2008 & May 2008 & Sep. 2008 & Feb. 2009 & Mar. 2009 & June 2009 & Oct. 2009 \\
\hline $\mathrm{s}$-crea $\mu \mathrm{mol} / \mathrm{L}$ & & 397 & 367 & & 406 & 509 & 386 & 278 & 309 & 212 \\
\hline s-urea mmol/L & & & & & 34.4 & 33.4 & 40.5 & 21.2 & 25 & \\
\hline $\begin{array}{l}\text { Cystatin C-based } \\
\text { eGFR } \\
\mathrm{mL} / \mathrm{min} / 1.73 \mathrm{~m}^{2} \\
\text { body surface }\end{array}$ & & & & & 24 & 16 & 17 & 21 & 20 & 24 \\
\hline $\begin{array}{l}\text { Iohexol Clearanc } \\
\mathrm{mL} / \mathrm{min} / 1.73 \mathrm{~m}^{2} \\
\text { body surface }\end{array}$ & & 9.7 & 13 & & 16 & & & 21 & & 23 \\
\hline Hemodialysis & $\begin{array}{l}\mathrm{X} \\
\text { Start }\end{array}$ & $\begin{array}{l}\mathrm{X} \\
\text { From } 3 \text { to } \\
2 \\
\text { times/week }\end{array}$ & $\begin{array}{l}\mathrm{X} \\
\text { From } 2 \text { to } \\
1 \\
\text { time/week }\end{array}$ & Stop & & $\begin{array}{l}\mathrm{X} \\
3 \text { acute } \\
\text { sessions }\end{array}$ & $\begin{array}{l}\mathrm{X} \\
1 \text { acute } \\
\text { session }\end{array}$ & & & \\
\hline
\end{tabular}

peripheral blood smear showed schistocytes and spherocytes and several reticulocytes. The clinical diagnosis was HUS and plasmapheresis was administered. The substitution fluid was plasma. However, the patient did not tolerate the treatment and became anuric with pulmonary edema. His creatinine level had now risen to $1247 \mu \mathrm{mol} / \mathrm{L}$. Hemodialysis was started acutely on the 12th of November and after that provided regularly three times per week. On the 23rd of November a kidney biopsy was performed. It showed severe vascular changes and several collapsed glomeruli compatible with the diagnosis of thrombotic microangiopathy and malignant hypertension. Immunofluorescence was negative.

The dialysis treatment continued and blood pressure treatment included 4 drugs (enalapril, candesartan, felodipine and metoprolol). The diuresis started to reappear and in January 2007 it was measured to $1700 \mathrm{~mL}$ between two dialysis schedules. He had received a central dialysis catheter on the 15th of November and an AV fistula was created in the end of January which however thrombotized. The size of the kidneys was not measured at this time point. In February 2007 an AV fistula was constructed in the upper arm, which worked perfectly and still is functioning well.

In May 2007 kidney transplantation was discussed and his sister was investigated as a donor. However, it turned out that she had had several DVTs and was thus deemed unsuitable for donation. The coagulation investigation of our patient indicated that he was heterozygote for APC resistance. The patient told us that he had good diuresis and therefore a measurement of kidney function was performed. A 48-hour iohexol clearance measurement showed a value of $9.7 \mathrm{~mL} / \mathrm{min} / 1.73 \mathrm{~m}^{2}$ body surface. The transplantation plans were changed. The dialysis schedule was instead reduced to twice per week. The patient's blood pressure was stable and well controlled by the four drugs and diuretics (Table 1).

In September 2007 it became possible to withdraw the EPO treatment due to a stable hemoglobin value of around $129 \mathrm{~g} / \mathrm{L}$.

In January 2008 a new 48-hour iohexolclearance measurement yielded a value of $13 \mathrm{~mL} / \mathrm{min} / 1.73 \mathrm{~m}^{2}$ body surface. The dialysis treatment was further reduced to once a week.
On the 13th of March, which was 514 days after the start of renal replacement, the dialysis treatment was withdrawn completely. The patient was monitored every week. He felt very well. In May 2008 the iohexol clearance was $16 \mathrm{~mL} / \mathrm{min} / 1.73 \mathrm{~m}^{2}$ body surface. The time between checkups was now extended to 2-3 weeks. S-creatinine varied between 320 and $410 \mu \mathrm{mol} / \mathrm{L}$.

In August the patient went to Thailand for a 4-week vacation. When he returned he was hypotonic and acidotic with uremic signs. His s-creatinine was 509 and urea was 33.4. After a couple of dialysis treatments and fluid he recovered from his symptoms.

In February 2009 he had a prolonged infection with bronchitis. The urea had increased to $40.5 \mathrm{mmol} / \mathrm{L}$ and creatinine to $386 \mu \mathrm{mol} / \mathrm{L}$. CRP was $71 \mathrm{mg} / \mathrm{L}$. He was given one dialysis treatment and antibiotics and recovered quickly.

In March 2009, thus one year after withdrawal of dialysis, his renal function was $21 \mathrm{~mL} / \mathrm{min} / 1.73 \mathrm{~m}^{2}$. His blood pressure (BP) was well controlled with BP 120/60. The $\mathrm{s}$-creatinine was $288 \mu \mathrm{mol} / \mathrm{L}$ and electrolytes were good. Cystatin C-estimated GFR was $22 \mathrm{~mL} / \mathrm{min} / 1.73 \mathrm{~m}^{2}$. In October 2009, thus 18 months after withdrawal, the renal function measured with iohexol clearance was $23 \mathrm{~mL} / \mathrm{min} / 1.73 \mathrm{~m}^{2}$, the Cystatin C-estimated GFR was $24 \mathrm{~mL} / \mathrm{min} / 1.73 \mathrm{~m}^{2}$, screatinine was $212 \mu \mathrm{mol} / \mathrm{L}$, and the patient was in very good health and working full time. His blood pressure was 123/73 and urine albumin/creatinine ratio $6.3 \mathrm{mg} / \mathrm{mmol}$.

The only disturbing factor was the slightly elevated LD, which was $4.6 \mu \mathrm{cat} / \mathrm{L}$, and elevated ASAT $2.76 \mu \mathrm{cat} / \mathrm{L}$. The CRP was normal, and the hemoglobin values were around $128 \mathrm{~g} / \mathrm{L}$, with no signs of hemolysis. A hepatic specialist stated that the enzymes are probably from muscles and most definitely not from the liver.

\section{Swedish Renal Registry (SRR) Data}

We found 39 patients who had recovered from their renal function, which was defined as dialysis for more than 365 days followed by recovery (SRR, http://www.snronline.se/). The data are presented in Table 2 and reveal that recovery 
TABLE 2: Characteristics of patients in the Swedish registry who recovered from renal function after more than 365 days on regular dialysis.

\begin{tabular}{llll}
\hline Diagnosis & Number & Dialysis treatment time (days) & Age (years) at start of dialysis treatment \\
\hline Renovascular disease with hypertension & 8 & $1126,989,821,514,763,593,475,558$ & $79,73,75,50,53,75,54,67$ \\
Chronic renal failure NUD & 7 & $2081,1117,852,1082,483,478,417$ & $71,79,72,70,71,44,63$ \\
Tubular/Cortical necrosis & 4 & $654,641,567,383$ & $45,58,67,61$ \\
HUS & 4 & $496,801,420,583$ & $82,49,6,43$ \\
Crescent GN & 2 & 1506,408 & 77,67 \\
Cholesterol embolism & 2 & 1102,621 & 57,72 \\
SLE & 2 & 995,496 & 21,29 \\
Polyarteritis & 2 & 710,444 & 75,71 \\
Sclerodermia & 2 & 484,664 & 41,52 \\
GN membranous 1, other 1 & 2 & 1415,464 & 71,59 \\
Wegener & 1 & 471 & 56 \\
Diabetes type ll & 1 & 401 & 70 \\
IN & 1 & 630 & 86 \\
Amyloidosis & 1 & 624 & 44 \\
\hline
\end{tabular}

occurred in 14 women and 25 men after 383-2081 days of dialysis treatment. Mean dialysis time was 726 (SD 360) days. A total of 29 patients were treated by means of $\mathrm{HD}$, six with $\mathrm{PD}$, and four with both $\mathrm{PD}$ and $\mathrm{HD}$ for various lengths of time. The largest groups were those with renovascular disease with hypertension (eight) and chronic renal failure of unknown causes (seven). Of the known diagnoses the most common were hemolytic uremic syndrome (four) and cortical/tubular necrosis (four). Other diagnoses included cholesterol embolism (two), polyarteritis nodosa (two), sclerodermia (two), crescent glomerulonephritis (two), and SLE (two). All patients were alive 3 months after withdrawal, thus it was not done to stop ESRD treatment before impending death.

Time without dialysis treatment after withdrawal ranged from 84 to 6431 days and the mean value was 1415 days, that is, 3.9 years.

\section{Discussion}

The Swedish registry revealed that $0.2 \%$ of patients recovered from renal function after more than one year of regular dialysis treatment. It may seem a low number. The Swedish Renal Registry (SRR) has been working since 1991. All units performing dialysis and/or kidney transplantation in Sweden report to the registry. Validation of the registry has shown a high accuracy and few patients are missed to be reported. Patients are supposed to be reported as soon as they enter renal replacement therapy by the local nephrologist (registry keyman). The basic criterion for a patient to be reported is that the renal insufficiency is regarded as chronic and based on a chronic kidney disease. When/if a patient has regained renal function, the keyman also reports this to the registry as soon as possible. The registry quality has been maintained by repeated feedback reports to the keymen, by yearly cross-sectional studies of the dialysis population, and by estimation of the number of unknown cases (validation). SRR uses the ERA-EDTA coding system. The patients' identities are known to us but the medical records have not been scrutinized.

If the rate of recovery from ESRD in the Swedish registry is regarded as low, this could be due to distinct criteria for chronic disease when entering the registry. Data on patients regarded as having an acute renal failure are deleted from the registry.

The data demonstrated that renovascular disease with hypertension was the most common diagnosis and obviously the kidneys can recover with good blood pressure control during dialysis treatment. However, a majority of the patients had no clear diagnosis that explained the reason for the renal failure. The most striking finding was the long renal replacement treatment time, the longest being 5.7 years and the mean treatment time being 2.0 years before renal replacement therapy was withdrawn. Is it difficult to stop dialysis treatment, especially after a long time? Have the kidneys recovered without it being detected? The study by Agraharkar et al. also shows that GFR based on creatinine clearance data at withdrawal was high, $29 \mathrm{~mL} / \mathrm{min}$ on average with a range from 9 to $51 \mathrm{~mL} / \mathrm{min}$ [1].

In our case report the diagnosis was thrombotic microangiopathy (TMA) with severe hypertension. The patient was classified as belonging to the group of renovascular diseases with hypertension, which is the largest group. Once his blood pressure had stabilized, the urine production started and the recovery process seemed to progress. A recovery phase of over six months has been described in acute hypertensive diseases by Yaqoob et al. [5].

Our own experience was that it is difficult to detect changes in renal function in dialysis patients. When we started to measure renal function with the injection technique, we found good values, which at first we did not believe to be accurate. However, regular measurements and the use of different methods for assessing renal function made us convinced. Both Cystatin C for estimating renal function and iohexol clearance for measuring function were used together 
with creatinine clearance. There was also a fear of stopping dialysis due to the risk of high potassium and/or pulmonary edema. We chose to gradually reduce the frequency of dialysis treatment. This seemed safe due to the close monitoring of the patient's renal function by the nurses and doctors at the dialysis department. The kidney function of our patient is now, 18 months later, in the CKD 4 stage. There is no specific treatment for his original disease and he still needs four different antihypertensive drugs, his blood pressure is depressed, and he has no significant albuminuria. It could be that he already had had a transplant, but the necessary investigations before a patient is accepted for transplantation delayed the procedure, which in this case seemed correct. This observation has been made by others [6].

A third group with recovery was autoimmune diseases and here probably immunosuppressive treatment had importance for the recovery procedure. Spontaneous remissions are found in HUS and membranous glomerulonephritis, which were also identified in the recovery group. The fact that HUS can take a long time before recovery has been described by Brunner et al., who reported two children where recovery occurred after 5 and 7 years and recommended caution before transplantation in this group [7].

Our message is that recovery of renal function could occur even after relatively long time on dialysis. It should particularly be expected in patients with relatively large or increasing urine volumes. Close monitoring and easy access to acute dialysis facilitate the decision to withdraw regular dialysis treatment. For patients who ask whether dialysis treatment is life long, the answer is that a few may recover from renal function and may stop dialysis, even after a relatively long time on dialysis treatment.

\section{Acknowledgments}

The authors want to thank the Sophiahemmet Foundation for financial support.

\section{References}

[1] M. Agraharkar, V. Nair, and M. Patlovany, "Recovery of renal function in dialysis patients," BMC Nephrology, vol. 16, pp. 4-9, 2003.

[2] R. Schmitt, S. Coca, M. Kanbay, M. E. Tinetti, L. G. Cantley, and C. R. Parikh, "Recovery of kidney function after acute kidney injury in the elderly: a systematic review and meta-analysis," American Journal of Kidney Diseases, vol. 52, no. 2, pp. 262-271, 2008.

[3] A.-M. Craven, C. M. Hawley, S. P. McDonald, J. B. Rosman, F. G. Brown, and D. W. Johnson, "Predictors of renal recovery in Australian and New Zealand end-stage renal failure patients treated with peritoneal dialysis," Peritoneal Dialysis International, vol. 27, no. 2, pp. 184-191, 2007.

[4] J. A. MacDonald, S. P. McDonald, C. M. Hawley, et al., "Recovery of renal function in end-stage renal failure-comparison between peritoneal dialysis and haemodialysis," Nephrology Dialysis Transplantation, vol. 24, no. 9, pp. 2825-2831, 2009.

[5] M. Yaqoob, P. McClelland, and R. Ahmad, "Delayed recovery of renal function in patients with acute renal failure due to accelerated hypertension," Postgraduate Medical Journal, vol. 67, no. 791, pp. 829-832, 1991.

[6] S. Siddiqui, M. Norbury, S. Robertson, A. Almond, and C. Isles, "Recovery of renal function after $90 \mathrm{~d}$ on dialysis: implications for transplantation in patients with potentially reversible causes of renal failure," Clinical Transplantation, vol. 22, no. 2, pp. 136140, 2008.

[7] K. Brunner, M. G. Bianchetti, and T. J. Neuhaus, "Recovery of renal function after long-term dilaysis in hemolytic uremic syndrome," Pediatr Neprhol, vol. 19, pp. 229-231, 2004. 


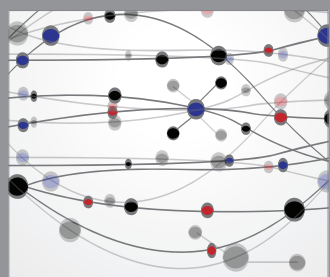

The Scientific World Journal
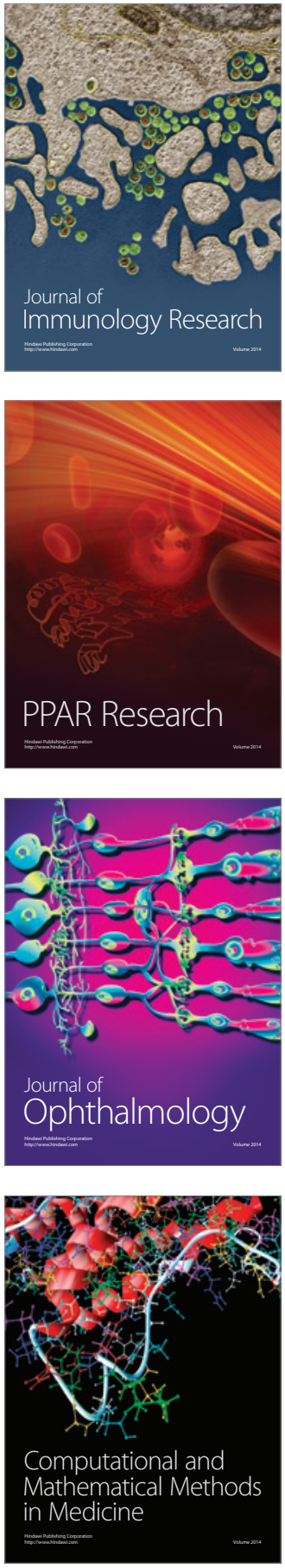

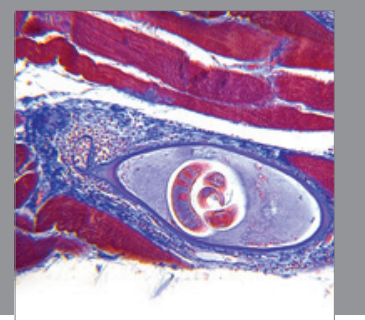

Gastroenterology

Research and Practice
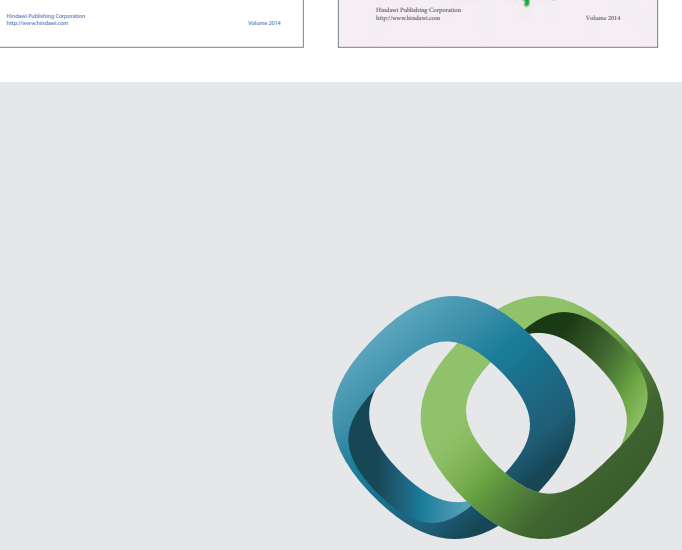

\section{Hindawi}

Submit your manuscripts at

http://www.hindawi.com
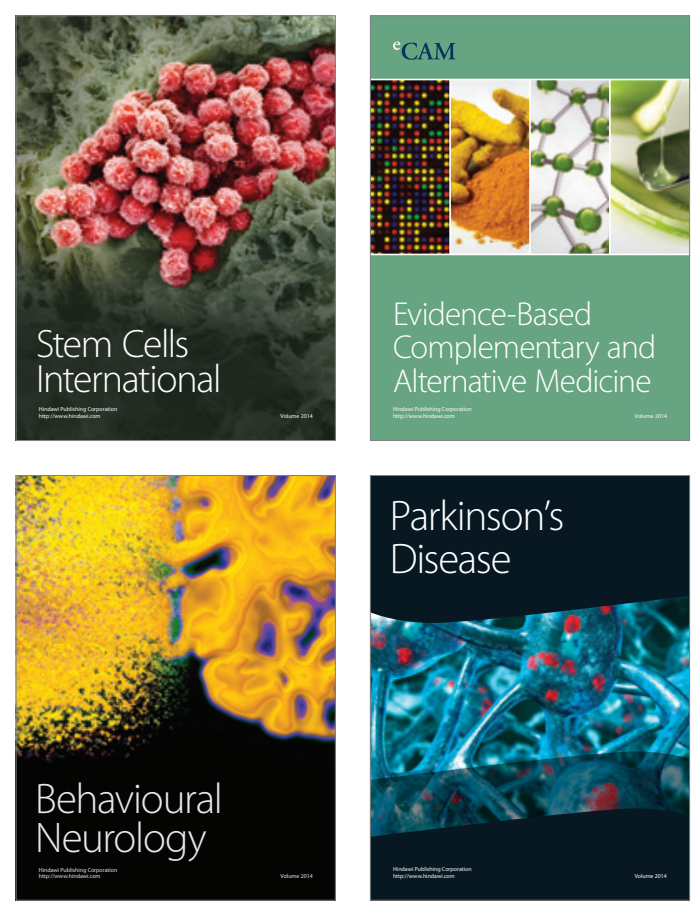

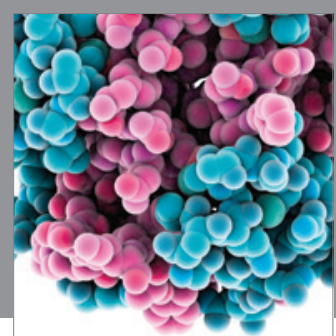

Journal of
Diabetes Research

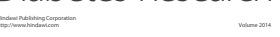

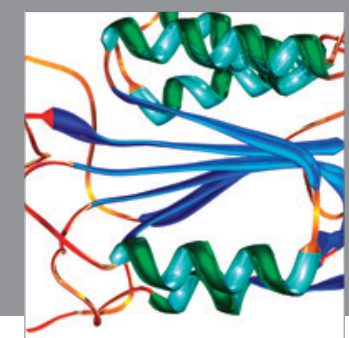

Disease Markers
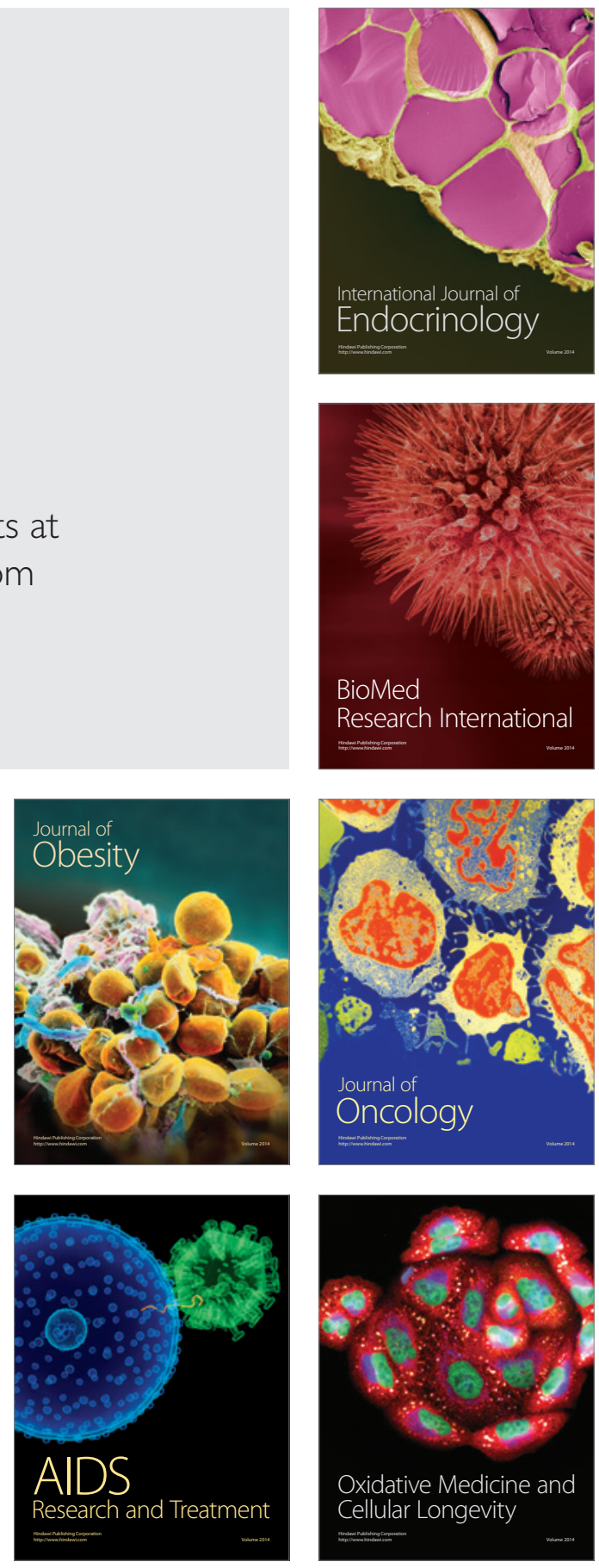